\title{
Arbitraje: naturaleza y definición
}

\author{
Mario Castillo Freyre \\ Ricardo Vásquez Kunze
}

Se suele conceder que una de las conquistas de mayor importancia en la administración de justicia es, históricamente, la pluralidad de instancia. También el azar en quién asume como juzgador de una causa juega un papel importante en lo que, se pretende, es la perfección de los procesos judiciales que buscan superar las injusticias de tiempos pretéritos signados por la barbarie. La publicidad de los juicios tiene la misma lógica, exorcizar el secreto que, se pontifica, es fuente de todo abuso. Y como el abuso es lo que la justicia trata de proscribir de la Tierra, exígese que la ley sea igual para todos y, por tanto, que nadie escape a los procedimientos que esta establezca previamente en materia de justicia, de tal modo que todos, por igual, sean medidos por la misma vara. De ahí que nadie pueda pagar su justicia sino que esta deba ser accesible a cualquiera merced a la gratuidad de su administración. Porque, finalmente, de todo esto se trata la justicia, según se dice, en una visión popular y política ${ }^{1}$ tan difundida que es moneda común y corriente en casi todas las constituciones ${ }^{2}$ del mundo occidental, y cuyo cuestionamiento constituiría una herejía contra la modernidad y un retroceso a las cavernas.

\footnotetext{
Mario Castillo Freyre es magíster y doctor en Derecho. Socio del estudio que lleva su nombre, es profesor de Obligaciones y Contratos en la Pontificia Universidad Católica del Perú, en la Universidad Femenina del Sagrado Corazón y en la Universidad de Lima. (www.castillofreyre.com)

** Ricardo Vásquez Kunze, abogado, trabaja en el Estudio Mario Castillo Freyre.

1 Según Fernando De Trazegnies, se trataría de la visión del Derecho liberal clásico de la administración de justicia cuyo dogma es «[...] ese monopolio de la función jurisdiccional del Estado que constituye una característica de la ideología moderna o liberal». De Trazegnies Granda, Fernando. «Los conceptos y las cosas: vicisitudes peruanas de la Cláusula Compromisoria y del Compromiso Arbitral». En El arbitraje en el Derecho latinoamericano y español, libro homenaje a Ludwik Kos Rabcewics Zubkowsky. Lima: Editorial Cuzco, pp. 546 y 547.

2 La Constitución Política del Perú de 1993 recoge esta visión de la justicia en el artículo 139 que regula la función jurisdiccional del Estado:
} 
Pues bien. Ninguno de los principios de la ortodoxia judicial expuestos hasta aquí como garantías inalienables de la administración de justicia en el mundo civilizado — que se dice es el mundo moderno - están considerados en esa otra manifestación de la justicia conocida como arbitraje. ${ }^{3}$ Ninguno. ¿Cómo es pues posible esto? ¿Es el arbitraje una herejía? ¿Acaso una manera reaccionaria de administrar justicia? ¿Una vuelta a la noche de los tiempos? ¿Una intolerable afrenta contra el progreso humano y sus adquiridos derechos? ¿Una sentencia de muerte contra la igualdad ante la ley fuente de toda justicia? ¿Tal vez la barbarie que acecha contra la civilización del Estado Nación?

Ninguna de estas preguntas podría obtener respuestas si no nos dedicamos a resolver el problema de la naturaleza del arbitraje, esa administración heterodoxa de la justicia que parece rebelarse contra doscientos años de revolucionarios dogmas. ${ }^{4}$

Nuestro propósito en las siguientes líneas es llegar a una definición cabal de arbitraje. Pero esto no es posible si no consideramos las aristas históricas, ideológicas y jurídicas de las teorías que lo explican, mejor dicho, que explican su naturaleza. Solo una vez descubierto el extenso horizonte que pone a prueba nuestro entendimiento de este fenómeno complejo, es que podremos aventurarnos a una definición. La iremos pues construyendo poco a poco, andando, en el camino, convencidos más que nunca de que es aquí, precisamente, donde solo se hace camino al andar.

Existen numerosas definiciones del arbitraje, acaso demasiadas, pero casi todas, por no decir todas, soslayan un elemento fundamental, a saber, que el arbitraje es el prototipo de la administración de justicia. ${ }^{5}$ Es la forma más

Artículo 139.- «Son principios y derechos de la función jurisdiccional: [...]

3. La observancia del debido proceso y la tutela jurisdiccional.

Ninguna persona puede ser desviada de la jurisdicción predeterminada por la ley, ni sometida a procedimiento distinto de los previamente establecidos, ni juzgada por órganos jurisdiccionales de excepción ni por comisiones especiales creadas al efecto, cualquiera sea su denominación.

4. La publicidad de los procesos, salvo disposición contraria de la ley. [...]

6. La pluralidad de instancia. [...]

16. El principio de la gratuidad de la administración de justicia y de la defensa gratuita para las personas de escasos recursos; $y$, para todos, en los casos que la ley señala. [...]».

3 «El arbitraje actual es una institución post-moderna (si por moderno entendemos el Derecho liberal clásico) [...] el arbitraje actual no quiere ser un mero auxiliar del Poder Judicial sino que pretende sustituirse al Poder Judicial en una serie de campos donde considera que el sistema formal y oficial no es eficiente». De Trazegnies, Fernando, ob. cit., pp. 546 y 547.

4 Dogmas que no son otros que los de la llustración dieciochesca y sus postulados de la separación de poderes, el judicial uno de ellos, y cuya sangrienta praxis tuvo su cenit con la Revolución Francesa.

5 Uno de los pocos autores que hemos encontrado que hacen mención al arbitraje como modelo primigenio de la administración de justicia es Jaime Guasp. Sin embargo, él aborda este tema a partir de la importancia histórica del arbitraje, y no desde el punto de partida de la definición. Ver Guasp, Jaime. El arbitraje en el Derecho español. Barcelona: Bosch, Casa Editorial, 1956, pp. 12-13. 
elemental de la jurisdicción, que por simple, también —y usando aquí un término tan caro a los tiempos modernos- es más eficiente.

En efecto. Hablar ya de eficiencia es aquí hablar en primer lugar de que se reconoce que la justicia por mano propia — la vendetta — es siempre más onerosa que la justicia impartida por mano de un tercero no involucrado en la pendencia. Y lo es, porque la vendetta, al obedecer a la ley del más fuerte para su éxito, puede ir siempre más allá del objeto que dio origen al litigio entre dos partes. Y entre perder algo y perderlo todo, inclusive la vida, es preferible lo primero, por cuanto, como mecanismo de solución de conflictos, en tanto el costo será siempre imprevisible para quien pierde, la vendetta es la encarnación de la ineficiencia social de la justicia.

Bien distinto es el caso de una sociedad que no está dispuesta a asumir el precio de una justicia tan costosa como la vendetta. En una sociedad tal, dos personas que tienen un conflicto de intereses cuya solución ha escapado al trato directo, esto es, que no se han podido poner de acuerdo sobre cómo dar fin a la controversia que las enfrenta, a satisfacción de ambas, recurren a un tercero. Este, por lo general ajeno al interés en disputa aunque no necesariamente ajeno a las partes, decide, al amparo de un orden jurídico determinado como telón de fondo, cuál de ambas tiene razón en el problema sometido a su sabiduría. Quien así dice el Derecho es, en términos coloquiales, un árbitro. Y su acción, un arbitraje. De esta forma celular de administrar justicia desciende, como habíamos dicho, la jurisdicción estatal de nuestros tiempos. Empero, solo en autorizada oposición a esta es que podemos definir cabalmente el arbitraje en su estado actual.

Ninguna definición que no parta de la premisa de que el arbitraje es una sustracción legalmente autorizada a la jurisdicción estatal, es una definición completa. ${ }^{6}$ Porque solo a partir de este hecho fundamental que es, en nuestro criterio, que los miembros de una comunidad jurídica puedan sustraerse a los órganos judiciales del Estado para resolver por otra vía un conflicto de derecho,

\footnotetext{
Este es el caso de definiciones de tratadistas como Humberto Briseño o Fernando Cantuarias y Manuel Aramburu. Briseño afirma que se configura el supuesto de arbitraje «[...] cuando dos o más sujetos acuerdan someter sus diferencias jurídicas a la decisión de un tercero. La discusión jurídica, la trilogía de sujetos, el acuerdo y la decisión del pleito, son las notas que permanecen constantes; [...]». BRISEÑO, Humberto. El arbitraje en el Derecho Privado. México: Imprenta Universitaria, 1963, p. 21.

De otro lado, Cantuarias y Aramburú definen el arbitraje como «[...] un medio privado de solución de controversias, mediante la intervención y decisión de terceros también privados, a quienes las partes de manera voluntaria han decidido someter su conflicto, aceptando de antemano acatar su decisión». Cantuarias Salaverry, Fernando y Manuel Aramburú YZAGA. El arbitraje en el Perú: desarrollo actual y perspectivas futuras. Lima: Fundación M.J. Bustamante De la Fuente, 1994, p. 39.

Como vemos, ninguna palabra sobre el hecho de que este medio privado de solución de controversias existe en virtud de que las partes se sustraen a la jurisdicción del Poder Judicial.
} 
es que podemos inferir que el arbitraje tiene una función análoga a estos. En otras palabras: que por medio del arbitraje se administra una justicia pero que esta no es igual a la que administra el Estado.?

Ahora bien, por un simple ejercicio de sentido común, consideramos que ninguna sustracción a la jurisdicción estatal tendría efectos prácticos, esto es, el efecto de zanjar jurídicamente una controversia entre dos partes, si esta sustracción no estuviera autorizada por el Estado. Pues resulta obvio que si el Estado prohibiera el arbitraje y, por tanto, tuviera por nulos todos sus efectos, este carecería de todo sentido en la medida en que el ganador jamás podría hacer valer un derecho que no solo no es reconocido, sino condenado por el ordenamiento jurídico. Rechazamos pues así las opiniones que le dan al arbitraje una existencia jurídica propia de su naturaleza, y afirmamos, por el contrario, que solo el derecho positivo puede establecer la existencia jurídica de cualquier fenómeno social. ${ }^{8}$

Y en efecto, así parece entenderlo en el Perú la Constitución Política de 1993 en el primer numeral del artículo 139, cuando reconoce al arbitraje una existencia jurídica de carácter jurisdiccional, de excepción a la jurisdicción unitaria y exclusiva del Estado. Aquí, la Ley de Leyes instituye expresamente una jurisdicción arbitral. ${ }^{9}$ Por tanto, para nuestro ordenamiento jurídico, el arbitraje es una forma oficial — aunque no estatal — de administrar justicia.

\footnotetext{
En esta línea se halla Juan Guillermo Lohmann, quien define al arbitraje como «[...] la institución que regula el acuerdo de voluntades por el cual dos o más partes deciden someter a uno o más terceros, que aceptan el encargo, la solución de un cierto conflicto de Derecho Privado respecto del cual dichas partes tienen capacidad de disposición, obligándose previamente a no llevar la controversia a los tribunales ordinarios sin el previo fallo arbitral, el cual deberá expedirse con arreglo a ciertas formalidades». LOHMANN LUCA DE TENA, Guillermo. El arbitraje. Biblioteca para leer el Código Civil. Lima: Fondo Editorial de la Pontificia Universidad Católica del Perú, 1987, volumen V, p. 39. (Las cursivas son nuestras).

También Sara Feldtein y Hebe Leonardi entienden que «[...] el arbitraje es un método de solución de controversias mediante el cual, en ciertas ocasiones, la ley permite sustraerse de la intervención de los órganos judiciales estatales». FeLDSTEIN, Sara y Hebe LEONARDI. El arbitraje. Buenos Aires: Abeldo Perrot, 1998, p. 12. (Las cursivas son nuestras).

8 Por eso cae en el error el jurista Guillermo Lohmann cuando afirma que el arbitraje tiene «[...] característica institucional en tanto que no le está permitido a los miembros del cuerpo social el poder derogarlo, sino de aplicarlo o no, dentro de las variantes y limitaciones que el ordenamiento interno establece». LoHmAnn LuCA DE TeNa, Guillermo, ob. cit., p. 39. La equivocación de Lohmann está en su confusa definición de institución jurídica, a saber, «[...] un conjunto de ideas y de elementos que, bajo reglas determinadas, disciplinan situaciones jurídicas, gobiernan comportamientos y establecen ciertas consecuencias de Derecho» (ibíd.).

Lo cierto es que un fenómeno social como el arbitraje o como cualquier otro se convierte en una institución jurídica porque el ordenamiento legal lo instituye jurídicamente. Ergo, ese mismo ordenamiento legal lo puede «destituir» jurídicamente, si cabe el término. Por tanto, afirmar que las instituciones jurídicas, como lo han sido en su momento la esclavitud, la debelatio o el mayorazgo, por poner solo unos ejemplos, no pueden ser derogadas, no es ni histórica ni lógicamente sostenible.

9 Artículo 139.- «Son principios y derechos de la función jurisdiccional:
} 
Este hecho legislativo nos introduce, doctrinariamente hablando, a la discusión fundamental de la naturaleza del arbitraje, a saber, si este tiene una esencia privada o una pública, o dicho en otros términos, si el arbitraje pertenece a la esfera de los contratos, a la de los procesos judiciales, o a ambas. ${ }^{10}$

No hay duda para nosotros de que para estar ante un supuesto de arbitraje, tiene que mediar un contrato que active este mecanismo de solución de controversias. El contrato entre dos sujetos de derecho que buscan que un tercero administre una justicia que no es la que administran los tribunales ordinarios del Estado, pero que está permitida por ese Estado, es un elemento esencial de cualquier definición de arbitraje. No hay arbitraje si no hay contrato. El asunto está en establecer si porque hay contrato no hay jurisdicción. Ese es el problema que se nos plantea.

Para la teoría contractualista, también llamada privatista del arbitraje, cuyos suscriptores son mentes de primer nivel en el mundo jurídico, ${ }^{11}$ la respuesta al problema planteado es que no hay jurisdicción si hay contrato. En buen romance, esta teoría le niega al arbitraje todo carácter jurisdiccional. ${ }^{12}$

Pero si quienes profesan una visión contractualista del Derecho fuesen consecuentes con sus tesis, estarían sin duda en serios aprietos conceptuales. Pues, no olvidemos que la jurisdicción $-\mathrm{y}$ siempre siguiendo aquí la lógica contractualista - sería fruto también de un contrato: el llamado contrato social. ${ }^{13}$ Esto no hace sino demostrar una de las grandes paradojas del contractualismo, a saber, asumir a rajatabla la naturaleza privada de los contratos cuando, precisamente, el contrato de los contratos no tiene esa simiente.

1. La unidad y exclusividad de la función jurisdiccional.

No existe ni puede establecerse jurisdicción alguna independiente, con excepción de la militar y la arbitral. [...]».

10 Independientemente de nuestra posición doctrinaria respecto de la naturaleza del arbitraje, queda claro que nuestro ordenamiento jurídico nacional suscribe la tesis del arbitraje como proceso jurisdiccional.

11 Defensores y divulgadores del contractualismo arbitral son en Francia los jurisconsultos Merlin, Fuzier-Herman, Weiss, Garzonnet y César-Bru y Brachet. En Italia suscriben esta tesis los grandes juristas Mattirolo, Chiovenda, Satta, Alfredo Rocco, Andrioli, Lugo, Pece, Furno y Costa. En España la avala Joaquín Escriche y, finalmente, en Argentina, David Lescano. Ver: VARGAS, Fernando. Naturaleza jurídica del arbitramento civil. Tesis para optar el grado académico de doctor en ciencias jurídicas. Bogotá: Pontificia Universidad Javeriana, 1964, pp. 35 y 36.

12 Ibíd., p. 35.

13 Uno de los teóricos más importantes de la tesis del «contrato social» es el filósofo ilustrado Jean Jacques Rousseau. Sobre esta dice: «»Encontrar una forma de asociación que defienda y proteja con la fuerza común la persona y los bienes e cada asociado, y por la cual cada uno, uniéndose a todos, no obedezca sino a sí mismo y permanezca tan libre como antes». Tal es el problema fundamental cuya solución da El contrato social [...]. Estas cláusulas, bien estudiadas, se reducen a una sola, a saber: la enajenación total de cada asociado con 
En efecto, el contrato social es el eje de cualquier aprehensión contractualista del mundo. Esta es la doctrina acuñada por el movimiento ilustrado del siglo XVIII cuyo fin no es otro que fundar la existencia del Estado y su soberanía, y, por ende, de su jurisdicción. Ya en otro trabajo hemos expresado, siguiendo a Kelsen, que nosotros no comulgamos con la tesis del contrato social como explicación para la existencia del Estado. ${ }^{14}$ Creemos más bien que esta tesis no explica, sino que pretende justificar la existencia de la soberanía y jurisdicción del Estado, porque busca justificar a su vez una filosofía que le es muy cara, la de la existencia de un estado de naturaleza donde los hombres son todos libres e iguales en derechos y, por lo tanto, solo a través de un contrato pueden obligarse a sí mismos a someterse a una jurisdicción que ellos han creado para su beneficio. No es el momento ni el lugar para discutir aquí el hecho de que es precisamente en ese estado de naturaleza que los hombres no son ni libres ni iguales, y mucho menos libres e iguales en derechos porque la naturaleza no otorga a ninguna criatura derecho alguno, $y$, consecuentemente, que el Estado y el Derecho, antes de emanar de un contrato (social), más bien parecen tener su origen en un estado de necesidad que impone el así llamado estado de naturaleza.

Lo que sí nos interesa señalar aquí es la contradicción de quienes, prisioneros lógicos de las tesis de un contrato como fuente primigenia de la jurisdicción, le nieguen precisamente a los contratos el poder para crearla. En síntesis, sí puede, dentro de la lógica contractualista del Derecho, haber jurisdicción por contrato. El pretendido contrato social es la mejor prueba de ello.

A estas alturas el asunto parece ir más que por el lado contractual, por el de qué entienden los contractualistas por jurisdicción. No creemos pues alejarnos de la verdad si afirmamos que para los autores que suscriben la tesis contractual del arbitraje, subsiste la tradición dieciochesca de que la jurisdicción es un atributo inherente a la soberanía del Estado, que es el paradigma de lo público. Así pues, porque la voluntad general lo ha querido es que los tribunales ordinarios

todos sus derechos a la comunidad entera, porque, primeramente, dándose por completo cada uno de los asociados, la condición es igual para todos; y siendo igual, ninguno tiene interés en hacerla onerosa para los demás [...]. En fin, dándose cada individuo a todos no se da a nadie, y como no hay un asociado sobre el cual no se adquiera el mismo derecho que se cede, se gana la equivalencia de todo lo que se pierde y mayor fuerza para conservar lo que se tiene [...]. Si se descarta, pues, del pacto social lo que no es su esencia, encontramos que queda reducido a los términos siguientes: «Cada uno pone en común su persona y todo su poder bajo la suprema dirección de la voluntad general, y cada miembro considerado como parte indivisible del todo»». Rousseau, Juan Jacobo. Obras selectas. Segunda edición. Colección Clásicos Inolvidables. Buenos Aires: Librería El Ateneo Editorial, 1959, pp. 853 y 854.

14 Ver CAstillo Freyre, Mario y Ricardo Vásquez Kunze. Analizando el análisis. Lima: Fondo Editorial de la Pontificia Universidad Católica del Perú, 2004, p. 59. 
del Estado tienen el poder de imperio, ${ }^{15}$ de hacer comparecer dentro del proceso, de grado o fuerza, a los testigos, de ordenar las diligencias que estimen conveniente dentro de la ley, de castigar a cualquiera que incumpla sus mandatos ${ }^{16} \mathrm{y}$, lo más importante, de ejecutar sus sentencias. ${ }^{17}$

Es cierto. El arbitraje carece de todos estos poderes atribuidos en los últimos doscientos años a la jurisdicción porque, como es obvio si seguimos la lógica de una tesis contractualista, en tanto emanado el arbitraje de un contrato entre dos partes, este no puede obligar más que a esas partes, a diferencia de un contrato suscrito en teoría por toda la sociedad. Pero esta interpretación soslaya el elemento esencial de la jurisdicción, a saber, el de ser el poder legalmente establecido para decir el Derecho. Y la ley puede sancionar que el Derecho sea dicho por los tribunales ordinarios de justicia que tendrán todos los poderes de apercibimiento propios del Estado, como también que el Derecho sea dicho fuera de la esfera pública, como es el caso del arbitraje. Aquí, el común denominador entre lo privado y lo público es la cualidad que a la jurisdicción no se le puede quitar, esto es, la autorización legal para decir el Derecho. En síntesis, para resolver jurídicamente una controversia.

Que el arbitraje, por ponerlo de alguna forma, se asemeja mucho a la jurisdicción que los contractualistas solo ven en la judicatura, se constata en los malabares conceptuales que hacen ellos mismos para no admitir el carácter jurisdiccional del arbitraje sin poder dejar de reconocerlo a su vez, en cierta

15 Poder que no tienen los árbitros y sus actos arbitrales y «[...] por tanto el arbitraje al que se concibe, en contraposición con la perfecta función jurisdiccional del Estado, como «la expresión de un más íntimo acuerdo, dirigido a la renuncia a la jurisdicción»». Ver CARNACINI, Tito. Arbitraje. Buenos Aires: Ediciones Jurídicas Europa-América, 1961, p. 22.

16 Esta es la posición de Chiovenda que dice que «La opinión sostenida por algunos escritores y dominante en la jurisprudencia, que atribuye al arbitraje carácter jurisdiccional, me parece profundamente equivocada. Basta observar que el carácter jurisdiccional debería aparecer durante el arbitraje, pero es justamente durante el arbitraje cuando la naturaleza meramente privada de la actividad arbitral se manifiesta en la falta de todo poder, que consienta a los árbitros hacer comparecer coactivamente a los testigos, Ilevar a cabo coactivamente una inspección ocular, etcétera.

Precisamente esta absoluta falta de poderes impide equiparar el arbitraje a uno de aquellos casos en que al particular le son confiadas funciones públicas porque al particular en estos casos le son conferidos por la ley los correspondientes poderes. El carácter del arbitraje consiste precisamente en esto: la ley deja libre a las partes que son las que conocen las condiciones y exigencias del caso concreto, de acordar que la materia lógica para la decisión sea preparada sin uso de poderes jurisdiccionales [...]». CHIOvenda, Giuseppe. Instituciones de Derecho Procesal Civil. Tomo I. Madrid: Editorial Revista de Derecho Privado, 1954, pp. 91 y 92.

17 Garsonnet y Cézar-Bru consideran que «Los árbitros son encargados de juzgar un litigio [...], pero los árbitros no son magistrados, pues les falta el carácter oficial. La autoridad de cosa juzgada y la fuerza ejecutiva que de su sentencia nacen, se refieren menos a esa sentencia que a la voluntad de las partes en virtud de la cual se dictó. Es una consecuencia del principio de que las convenciones legalmente celebradas son una ley para las partes». En VARGAS, Fernando, ob. cit., p. 36. 
medida. Jurisdicción especial le llaman algunos, ${ }^{18}$ afinidad lógica con el proceso, otros. ${ }^{19}$ Lo cierto es que desde el momento mismo en que se afirma que la decisión o laudo a que llegan los árbitros sobre un determinado problema sometido a su consideración, solo puede ser ejecutado por un juez ordinario, quien deberá cumplir la decisión arbitral como si hubiera sido dictada por otro juez ordinario — y ahí radica, en los alcances ejecutivos entre laudo y sentencia, una de las mayores diferencias entre jurisdicción arbitral y estatal—, se está admitiendo analógicamente la calidad de jueces de los árbitros y las características procesales del arbitraje.

Pero que se admitan analógicamente no significa que sean exactamente. Un arbitro es como un juez porque ejerce la misma función social, pero no es un juez. Un arbitraje es como un proceso porque como en este se dirime jurídicamente una controversia, pero no es un proceso judicial. De ahí que, así como hemos cuestionado hasta aquí el extremismo simplista del contractualismo arbitral, hacemos también lo mismo con las tesis de quienes, sin duda queriendo guardar ideológicamente incólume la majestad y la soberanía del Estado Nación, sostienen que la naturaleza del arbitraje es, sin más, jurisdiccional. Nosotros pues rechazamos la teoría procesalista del arbitraje $\mathrm{e}^{20}$ que, como hemos referido líneas arriba, suscribe erróneamente - a grandes rasgos- nuestra Constitución Política.

Y la rechazamos porque, a todas luces, es un error sostener, como lo hace esta teoría, el carácter público de la función arbitral apoyándose en que es la ley la que le da existencia jurídica en tanto mecanismo de solución de controversias $^{21}$ y que, por tanto, los árbitros son funcionarios públicos que imparten

18 Matirolo entiende que el juicio de los árbitros constituye una forma de jurisdicción especial, otorgada a estos en virtud de un compromiso. Ver VARGAS, Fernando, ibíd., loc. cit.

19 «Lo que las partes sustituyen al proceso es afín al proceso en su figura lógica, es decir, en ser una resolución de controversias mediante un juicio ajeno [...]». CHIOvendA, Giuseppe, ob. cit., pp. 91-92.

20 También conocida como teoría jurisdiccional, el procesalismo arbitral cuenta con importantes suscriptores. En la Italia del siglo XX, esta tesis ha sido defendida por Ludovico Mortara, Ugo Rocco, Capaccioli, Jaefer, Boscarelli, Vechione, Pietro Bonfante, Vicenzo Galante, Prospero Fedozzi, Ghirardini y Galgano. En Francia, Laurent, Lainé, Boncene, Glason, Tissier y Morel han sido sus más reconocidos apólogos. Asimismo cuenta con el beneplácito de los españoles Reus y Manresa, Antonio Malaver y Rafael de Pina y, en América, con la pluma del chileno Patricio Aylwin Azocar. Ver Vargas, Fernando, ob. cit., p. 29.

21 Esta es la posición de Ludovico Mortara, quien es considerado el mejor exponente de la doctrina jurisdiccionalista y que sostiene que el arbitraje realmente existe porque la ley lo ha instituido y por tal razón esta misma ley es la que le ha concedido a las partes, que han sido investidas con un cierto grado de la soberanía inherente al Estado, el poder necesario para resolver un conflicto con absoluta autoridad, por medio de un compromiso. Así, según Mortara, el poder de los árbitros no nace del simple nombramiento que hacen las partes de ellos, en la medida en que las partes no poseen tal facultad, porque no podrían otorgar lo que no les es propio. Ver VarGas, Fernando, ob. cit., pp. 31 y 32. 
justicia y sentencian a nombre del Estado en un proceso que forma parte de la unidad y exclusividad de la función jurisdiccional de ese Estado. ${ }^{22}$

¿Y qué hay del contrato de arbitraje? Como resulta evidente, esta interpretación quita todo carácter privado al arbitraje, lo cual ofende el sentido común. Porque si se trata de argumentar que todo aquello que la ley autoriza tiene carácter público, entonces no podría existir como concepto siquiera el derecho privado, ni qué decir los contratos, habida cuenta de que estos tienen existencia y efectos jurídicos porque la ley así lo establece explícita o tácitamente. Así pues, aunque la premisa de que es la ley la que debe autorizar la institución arbitral para que esta tenga efectos jurídicos es verdadera, la conclusión de que el arbitraje tiene una naturaleza jurídica pública, propia de las funciones del Estado, es falsa. Estamos pues ante una falacia.

Una segunda observación que no debe ocuparnos más que un par de líneas, habida cuenta de que es una de las más manidas atingencias que se hacen contra la naturaleza jurisdiccional del arbitraje, es que los árbitros no pueden sentenciar porque las sentencias tienen una calidad ejecutiva que no poseen ni podrán poseer jamás los laudos arbitrales. Cuando los posean, entonces ya no serán laudos, sino sentencias dictadas por un clásico órgano jurisdiccional del Estado.

Nótese además - y volvemos aquí al principio de este ensayo- la enorme contradicción que encierra hacer del arbitraje una institución de jurisdicción estatal que carece, sin embargo, de los más importantes principios, derechos y garantías de la jurisdicción estatal como son la instancia plural, ${ }^{23}$ el juez natural,

22 Ugo Rocco considera que en el arbitraje, el particular asume y ejerce una función pública o un servicio público (como en el supuesto en que un ciudadano arreste al autor de un delito sorprendido en flagrancia, o que en el caso de calamidad u otra situación análoga, presta ayuda a la fuerza pública), que no son otras que las clásicas funciones jurisdiccionales del Estado. En tal virtud, Rocco estima que el laudo o decisión arbitral se constituye en una verdadera sentencia provista de fuerza obligatoria, a la que solo le faltaría la fuerza ejecutiva. Esta le debe ser atribuida por el decreto del pretor, necesaria a su vez por el hecho de que el laudo es expedido por un órgano que no pertenece a la jurisdicción ordinaria.

El jurisdiccionalista Capaccioli no va tan lejos como Rocco. Niega que el laudo tomado en sí mismo tenga la naturaleza de una sentencia; sin embargo le reconoce a esta el carácter de un acto institucional destinado a integrarse con la providencia de homologación del juez togado, por lo que, en este sentido, le otorga el carácter de acto público y hasta de acto jurisdiccional, así como serían públicas y hasta jurisdiccionales la función y actividad de los árbitros. Ver CARNACINI, Tito, ob. cit., pp. 21-23.

23 La Ley General de Arbitraje establece la posibilidad de apelación del laudo, previo acuerdo de las partes en la Cláusula Arbitral o en el Acta de Instalación del Tribunal Arbitral. Sin embargo, en la realidad, las partes nunca pactan apelación. Nótese lo curioso que resulta que la pluralidad de instancias puede ser objeto de toma y daca en el arbitraje, situación esta imposible de concebir en la jurisdicción estatal. La Ley General de Arbitraje también contempla la posibilidad de anulación del laudo en el Poder Judicial. Mas esto no puede interpretarse como una pluralidad de instancias porque el Poder Judicial no es otra instancia dentro de la jurisdicción arbitral, sino otra jurisdicción totalmente distinta. La pluralidad de instancia debe entenderse pues dentro de una misma jurisdicción. 
el procedimiento legal previamente establecido por la ley, la publicidad en los procesos, la igualdad ante la ley y la gratuidad de la administración de justicia, entre otros.

La diferencia entre uno y otra no solo se manifiesta en la contradicción de que el arbitraje dé la espalda a estos tótems de la función jurisdiccional del Estado, sino, además, hipotéticamente por lo menos, en un enfrentamiento que podría condenar a la misma jurisdicción estatal a la extinción social en varias áreas del Derecho, habida cuenta de que nada impide que el arbitraje se difunda masivamente y los principios y garantías bajo los cuales dice el Derecho de forma privada, terminen imponiéndose a los de la jurisdicción del Estado. Así, que uno puede terminar enfrentándose a la otra sustituyéndola en los usos y costumbres. Quiere decir que no son lo mismo, aunque cumplan una función similar.

No son iguales, pues, ni conceptualmente ni en los hechos, jurisdicción estatal y arbitraje. Queda claro así para cualquiera la diferencia.

Entonces, ¿de qué estamos hablando finalmente? ¿Cuál es la naturaleza jurídica del arbitraje si hemos anatematizado la tesis contractualista y condenado la jurisdicionalista o procesalista? ¿Significa esto acaso que el arbitraje no tiene naturaleza contractual ni jurisdiccional? Todo lo contrario. El arbitraje tiene ambas naturalezas jurídicas que se manifiestan y se aprehenden, cada una en su respectivo contexto. La contractual, en el momento del alumbramiento del arbitraje, cuando este nace, permitido por la ley, para el propósito ad hoc querido por las partes, esto es, poner fin a una controversia de derecho. La jurisdiccional, de otro lado, en el posterior desarrollo que permitirá realizar ese propósito ad hoc. La realización del propósito pone término al carácter contractual y jurisdiccional del arbitraje.

Esta posición nuestra se nutre de la tesis conocida como teoría intermedia o sincrética. ${ }^{24} \mathrm{El}$ nombre es desafortunado sin embargo, porque no se trata aquí de conciliar jurídicamente doctrinas que son, por su ideología, irreconciliables —una abraza la autonomía de la voluntad mientras la otra adora la soberanía del Estado — haciendo concesiones a cada una. Cualquier tesis fruto de un ensamblaje semejante no daría por resultado más que un monstruo jurídico y nosotros no queremos apadrinar monstruos.

Así pues, en el hecho de hallar en el arbitraje dos naturalezas, está, más que cualquier visión alambicada del Derecho, la realidad monda y lironda.

24 Esta teoría tiene como fundamento rechazar las posiciones extremas en torno a la naturaleza del arbitraje, es decir, descarta la teoría contractualista y la jurisdiccionalista tomadas individualmente. En este sentido, la postura intermedia se nutre de ambas teorías, tomando lo que considera correcto de cada una de ellas. Son exponentes del sincretismo arbitral los juristas Dalloz, Mongalvy, Bernard, Robert, Margarette Landrau, Louis Cremieu y Garbagnati. Ver VarGas, Fernando, ob. cit., p. 41 y CaRCANACINI, Tito, ob. cit., pp. 22 y 23. 
De ahí es que nosotros rebauticemos la tesis en cuestión como teoría realista del arbitraje.

En efecto. Es porque la realidad así lo expone, que es imposible negar que el nacimiento del arbitraje solo tiene lugar en la medida en que los particulares, por un acto voluntario amparado por la ley, deciden someter sus conflictos, presentes o futuros, al arbitraje. Así, únicamente se someterá a esta institución una controversia en tanto exista un contrato que faculte la actuación de los árbitros. Esto significa que, ausente el contrato, no será posible que se proceda a resolver controversia alguna por medio del arbitraje, salvo que la ley sancione su carácter obligatorio.

Pero la realidad no solo da fe de eso. También atestigua, sin ninguna duda, que una vez nacido el arbitraje, este se desarrolla en un proceso que requiere que los actos de los árbitros sean considerados por las partes y los terceros como actos de carácter jurisdiccional, de forma tal que lo resuelto por los árbitros tenga la fuerza definitiva de las resoluciones judiciales, como si fueran una sentencia. Si no, ¿cuál sería el objeto y la gracia del arbitraje?

No es realista, pues, negar el carácter jurisdiccional del arbitraje. Que los laudos no tengan fuerza ejecutiva no invalida la esencia de un acto jurisdiccional, a saber, que un tercero autorizado por la ley, sea este funcionario público o sujeto particular, diga quién tiene derecho y quién no en un asunto sometido a su juicio. Y lo real es también que el Estado no puede renunciar jamás a esa prerrogativa ejecutiva de la justicia, es decir, a ejecutar lo que es justo, haya sido dicho privada o públicamente, porque lo contrario sería instituir la justicia por mano propia o vendetta y atentar así contra el propio sentido de su existencia.

Solo a estas alturas, habiendo hecho este largo recorrido doctrinario y ventilado la naturaleza jurídica del arbitraje, estamos en condiciones pues de definirlo.

El arbitraje es la manifestación más elemental de la administración de justicia. En el presente estado de la evolución histórica, solo puede ser concebido como una sustracción legalmente autorizada a la jurisdicción estatal. Se origina mediante un contrato privado por el que dos o más sujetos de derecho deciden someter un conflicto con relevancia jurídica a la decisión resolutoria, definitiva y exclusiva, de uno o más terceros denominados árbitros, que son designados por las partes o por algún mecanismo establecido por ellas. Así, la decisión resolutoria de los árbitros o laudo, será de cumplimiento obligatorio para las partes en virtud de que el ordenamiento jurídico establece que los contratos son ley para las partes. La ejecución de la decisión arbitral, en caso esta sea necesaria, queda siempre en manos del Estado.

Ha llegado la hora pues de dar respuesta a las preguntas que abrieron el presente capítulo. ¿Es el arbitraje una herejía como aprehensión de la administración 
de justicia? Todo depende del cristal con que se mire. Si lo hacemos desde el prisma del dogma de la soberanía del Estado Nación y de los principios ideológicos que lo inspiran, como el de la unidad y exclusividad de la todopoderosa función jurisdiccional del Estado, sí, es una herejía. Si por el contrario miramos los feos tintes con que ese dogma y sus principios manchan y degradan hoy con la ineficiencia la administración contemporánea de la justicia, hasta convertirla en una injusticia, sin duda que la herejía es esta y no el arbitraje.

¿Es acaso el arbitraje una manera reaccionaria de administrar justicia? Pues claro que lo es. Porque todo aquello que no funciona $-\mathrm{y}$ la centralización de la función jurisdiccional del Estado está atascada hace mucho en el pantano de sus propios dogmas, incapaz de solucionar los problemas que el hombre presenta y sus circunstancias le plantean- da lugar a una reacción. Y la reacción es positiva cuando «La congestión de causas en los tribunales y la ineficiencia que resulta de ello, las complejidades de la vida comercial moderna que exigen muchas veces conocimientos económicos o tecnológicos avanzados para entender el meollo de una controversia, han llevado a una decepción de la teoría de la hegemonía del Poder Judicial [...]». ${ }^{25}$

¿El arbitraje es una vuelta a la noche de los tiempos y una intolerable afrenta contra el progreso humano y sus adquiridos derechos? Bueno, la clave está en el bello tiempo que haga en la noche y el feo que aplaste el día. Y todo parece indicar que es en ese feo día que esos adquiridos derechos afrentan el progreso humano encarnado en la justicia.

¿Es el arbitraje acaso la sentencia de muerte contra la igualdad ante la ley fuente de toda justicia? Que responda la posteridad. Nosotros, sin embargo, podemos preguntar a su vez si no será que la igualdad ante la ley ha sido la sentencia de muerte de la justicia. Que responda también a esto la posteridad.

Finalmente, ¿es el arbitraje la barbarie que acecha contra la civilización del Estado Nación? Ninguna barbarie puede ser aquello que la civilización del Estado Nación tomó por modelo para administrar justicia. El hecho histórico es que las campanas doblan ya por el Estado Nación como doblaron en su tiempo por otras formas de organizaciones jurídicas y políticas.

No han doblado, por lo visto, por el arbitraje.

25 De Trazegnies Granda, Fernando, ob. cit., pp. 546 y 547. 